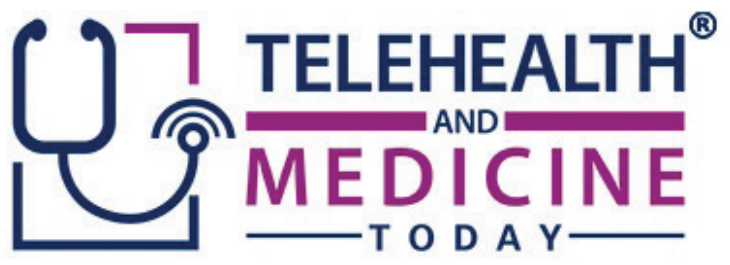

\title{
Applying Servant Leadership in a Telehealth Environment
}

\section{Allison Eagen}

Affiliation: Jacksonville University, Jacksonville, Florida

Corresponding Author: Allison Eagen: allison.eagen@encompasshealth.com

Keywords: Physical Therapy, Servant Leadership, Telehealth, Healthcare, Pandemic, COVID19.

Section: Use Cases

$\mathrm{S}$ ervant leadership emphasizes that leaders be attentive to the concerns of their followers, empathize with them, and nurture them." In this leadership practice, the leader puts followers first working to "serve the greater good of the organization, community, and society at large." Service providers such as healthcare workers often times display this form of leadership, as the heart of their mission and work is to serve their clients and those under their care. Throughout my professional career as a physical therapist, I have exhibited servant leadership through my direct care to my patients. This care focused on their immediate needs and additionally working to empower them to focus on their own health and become autonomous for their own recovery and care.

At the start of the COVID19 pandemic, I was offered the opportunity to work as an independent contractor for a physical therapy company solely providing physical therapy services through a telehealth platform. While financially this was a rewarding opportunity, the opportunity was also a new challenge for several reasons. First, despite being a physical therapist for 17 years, I had not provided direct patient care for several years. Second, at first thought, providing physical therapy, which is usually delivered using hands-on techniques, would require a lot of creativity to perform this care virtually through a telehealth platform. Third, outside my personal issues, delivering telehealth physical therapy was also a new and challenging concept for the patients.

Despite these challenges, there was a tremendous need for physical therapy service during this time, as brick and mortar outpatient therapy clinics closed temporarily due to health concerns within society. Patients who were receiving care, many of whom were frontline healthcare employees or essential workers, still needed the service to recover from their work injuries so that they could return to work. Furthermore, the patients had a concurrent psychological need to maintain the hope that they had to return to work as well as the social benefits obtained from 
communicating their issues and seeking resolution. The required lockdown that many were facing was having a psychological impact on individuals. In response to these tremendous societal needs, I responded to the call to action.

Looking back at the last 4 months, I used servant leadership methods to successfully respond to this new challenge and effectively deliver the needed patient care. In the very first session with a patient, physical therapy begins with an evaluation, which requires an extreme level of listening as the patient describes their physical concerns, limitations, and deficits. Given the fact that these patients were worker's compensation patients, their accident occurred at work and their intention was to return to work. In addition to their physical concerns, oftentimes these patients had psychological concerns as well such as fear, despair, and even grief of their immediate loss. While I am not a psychologist, just listening to an individual express these feelings positively impacts their ability to heal. A telehealth platform can present an additional challenge compared to face-to-face communication, as the normal gestures and body language typically used to support the interaction may be missed or overlooked through the audiovisual components or latency issues. As such, it was extremely important for me to demonstrate a fully tuned-in level of listening to not only hear what the patient was saying but also convey this listening engagement to the patient. These challenges also provided an opportunity for the patient and provider to build rapport as they work together within the telehealth environment.

In order to gather the trust of the patient, it was also important to exhibit empathy so that the patient felt and believed that I understood what they were going through. Delivering empathetic care adds value to the care provided, instilling that you understand the patient's point of view.
While healthcare providers generally have skills in this area, empathy can continue to develop through life experiences and personal growth.

About 3 years ago, I had a back surgery, was out of work, and significantly limited for several months. At that time, I had to have physical therapy. My empathetic skills significantly improved from this experience. While each individual's experience is unique, I oftentimes share this experience with my patients to communicate my empathy.

Throughout the patient's plan of care, I try to physically stimulate their healing capabilities. On the surface level, my expertise, techniques, and directions provided to the patient guide them through activities and movements designed to promote their healing. However, during this challenging time, the patient's needs and my efforts extended to a deeper level, as I worked to additionally promote their emotional healing. Their emotional needs related to their immediate work situation as well as their emotional healing in response to the global pandemic. I was challenged to additionally stimulate hope and optimism during this challenging time. Since we as a society were venturing into unchartered waters, the healing journey that the patient and I traversed during our sessions was a mutual journey. As I worked to heal my patients, I was also inspired by their growth and recovery.

As the patient continued throughout their treatment sessions, my characteristics of awareness and foresight become paramount. I needed to be acutely attuned and receptive to the patient's response to treatment and response to my methods to inspire and provide care. It was important to be continually mindful that the telehealth platform was also a new method for the patient. Delivering care through the telehealth platform required greater emphasis on my own 
body language and facial expressions as well as my interpretation of the patient's non-verbal responses. Additionally, with this new delivery method, the patient did not know what to expect or what the future had in store for them. Some patients were new to worker's compensation and did not know how the process worked. Others were more familiar with the process, but were unsure how the typical process would be modified because of the pandemic. It was my responsibility to help guide the patient through the process and look out for their best interest. After initially obtaining the patient's trust, I maintained their trust by foreseeing the future events or expectations for the patient and appropriately preparing them to handle the future. I had to prepare the patient for the future conversations they would have with their doctors or employers. Many of these future appointments with additional providers would also be performed within the telehealth environment. Part of my leadership role was to empower the patient so that they could be autonomous in these situations and appropriately communicate their needs.

Throughout my care with the patient, I conceptualized their needs related to their resolution of their physical deficits and additionally how their deficits would impact their work function to determine what they physically needed to do to return to job-specific duties. As such, we were aiming for function that exceeded normal function with the capacity to respond to the additional stress of their work environment. The patient may do a good job communicating their work-related needs or I may be familiar with the job requirements. In a brick and mortar environment, there are multiple tools and props that can easily be used to design activities which are portions of the broader job requirements designed to gradually improve the patient's ability to perform their job. Through the telehealth platform, this conceptualization for designing simulated activities, which could be communicated to the patient and performed at home, required fully listening to truly understand their needs and work requirements as well as continually obtaining feedback from the patient to ensure that the program was appropriately targeted to build the function required for their return to work. This process required significant imagination and creativity to think outside the box as well as continuous encouragement to guide the patient to comply with the program to ensure long-term benefits of achieving their goals and ability to return safely to work.

While each individual was unique in their specific needs, skills, and intrinsic capabilities, my role as a servant leader was to support each individual to become their best self. Throughout my relationship with each patient, my goal was to promote their physical, personal, and professional growth. As the patient and I reached our final stages of our journey together and they were approaching discharge, I was rewarded by seeing them meet their goals and return to work. More so, I was impassioned by their growth as they became healthier and more autonomous individuals. Together, we had a positive impact on society throughout this process. The telehealth platform served as a valuable healthcare delivery model during this specific time of need and exceeded my expectations for developing a plan of care with the specificity and challenge level needed to meet the patient's goals. By using servant leadership to guide the patient within the telehealth environment, telehealth delivery also served as a valuable resource for instilling the hope, optimism, and motivation the patient needed to respond to their challenges.

Conflicts of Interest: The author declares no potential conflicts of interest. 
Contributors Contributions: The author

declares that he is the sole author of this article.

Funding Statement: No funding was received from any source for writing this article for publication.

\section{References}

1. Northouse PG. Leadership: Theory \& practice. 8 th ed. Thousand Oaks, CA: Sage; 2015.
Copyright Ownership: This is an open access article distributed in accordance with the Creative Commons Attribution Non Commercial (CC BY-NC 4.0) license, which permits others to distribute, adapt, enhance this work non-commercially, and license their derivative works on different terms, provided the original work is properly cited and the use is non-commercial. See: http://creativecommons.org/licenses/ by-nc/4.0. 